Research Article

\title{
Prevalence and Determinants of Exclusive Breastfeeding Practice among Mothers of Children Aged 6-24 Months in Hail, Saudi Arabia
}

\author{
Mashail Basheir Alshammari ${ }^{1}$ and Hassan Kasim Haridi ${ }^{2,3}$ \\ ${ }^{1}$ Family \& Community Medicine Joint Program, Hail, Saudi Arabia \\ ${ }^{2}$ The Designated Institutional Official (DIO) for Academic Affairs \& Postgraduate Studies, Health Affairs, Najran, Saudi Arabia \\ ${ }^{3}$ Research Department, Health Affairs, Hail Region, Saudi Arabia
}

Correspondence should be addressed to Hassan Kasim Haridi; hassankasim@hotmail.com

Received 10 August 2020; Revised 14 March 2021; Accepted 17 March 2021; Published 28 March 2021

Academic Editor: Abdel Halim Salem

Copyright (c) 2021 Mashail Basheir Alshammari and Hassan Kasim Haridi. This is an open access article distributed under the Creative Commons Attribution License, which permits unrestricted use, distribution, and reproduction in any medium, provided the original work is properly cited.

\begin{abstract}
Background. The WHO recommends that infants should be exclusively breastfed for the first six months of life to achieve optimal growth, development, and health. Nonadherence to exclusive breastfeeding (EBF) depends largely on the individual, sociocultural context, and institutional factors. The aim of this study is to estimate coverage and factors associated with adherence to EBF among mothers in the urban Hail region, Saudi Arabia. Methods. A cross-sectional study was carried out during February-June 2019 among 450 mothers of children aged 6-24 months attending immunization and well-baby clinics in 6 primary healthcare centers in Hail city. A pretested structured questionnaire was used to interview the consented participants. Results. The majority of mothers (72.9\%) were aware of EBF; $24 \%$ reported initiation of breastfeeding within one hour after delivery; however, $71.1 \%$ did during the first 24 hours. The majority $(76.8 \%)$ fed colostrum to their newborn; nevertheless, $50.1 \%$ had given a prelacteal feeding. Mothers who reported EBF practice were 50.7\% (CI 45.9-55.4). The adjusted logistic regression analysis revealed that mother's awareness about EBF (aOR 3.03; 95\% CI 1.78-5.18), antenatal care received at the governmental facility (aOR 2.63; 95\% CI $1.28-5.41$ ), breastfeeding a previous child (aOR 2.42; 95\% CI 1.46-4.03), counseling received after delivery (aOR 2.47 ; $95 \%$ CI 1.34-4.53), and colostrum feeding given (aOR 4.24; 95\% CI 2.31-7.77) were positively associated with EBF practice. On the other hand, mother's education (OR 0.39; 95\% CI 0.15-0.99), higher family income (aOR 0.04; 95\% CI 0.00-0.31), and practice prelacteal feeding (aOR 0.61; 95\% CI 0.38-0.97) were negatively associated with EBF practice. Conclusion. EBF rate in urban Hail is still far below WHO recommendations. Efforts to strengthen mothers' counseling/support during antenatal care and immediately after delivery are needed to promote EBF practice, especially in the private sector.
\end{abstract}

\section{Introduction}

Breastfeeding is an investment in health, not just a lifestyle decision. It provides unmatched health benefits for babies and mothers. Infants who are breastfed have reduced risks of asthma, obesity, Type 1 diabetes, severe lower respiratory disease, acute otitis media, sudden infant death syndrome, gastrointestinal infections, and necrotizing enterocolitis for preterm infants $[1,2]$. Studies have shown also an inverse relationship between exclusive breastfeeding (EBF) and infant mortality rates in developing countries [3], so that
WHO described EBF as the single most effective intervention to improve the survival of children [4]. Women who breastfeed also have a reduced risk of high blood pressure, Type 2 diabetes, ovarian cancer, and breast cancer $[1,2]$.

The WHO and the United Nations Children's Fund (UNICEF) recommend that children be exclusively breastfed for the first 6 months of life-meaning no other foods or liquids are provided, including water [1]. However, the global picture falls short of these standards, as only about $40 \%$ of infants aged 0-6 months old are exclusively breastfed [5]. This is far below the widely accepted "universal coverage" target 
recommended by WHO/UNICEF that there should be $90 \%$ $\mathrm{EBF}$ in children less than 6 months in developing countries $[6,7]$.

The WHO in the Eastern Mediterranean region set a regional strategy on nutrition 2010-2019 that the percentage of women exclusively breastfeeding for the first 6 months increased by $50 \%$ [8]. The World Health Assembly (WHA) in 2012 set this target to be reached at the global level by 2025 [9].

There is insufficient data available on breastfeeding in Saudi Arabia. An earlier study in 2009 reported a declining trend of exclusive breastfeeding from $90 \%$ to $30 \%$ at the age of 3 months [10]. To estimate the EBF rate in Saudi Arabia, a systematic review published in 2014 found high variation among studies, which ranged from $0.8 \%$ to $43.9 \%$, and clinched that the EBF rate could not be accurately determined due to the lack of clear definitions and the nature of study design [11]. Furthermore, the WHO does not report any breastfeeding data in the country profile because there are no national data on breastfeeding [12].

Although there are several studies identifying rates and factors influencing EBF, still there is a need to assess rates and understand the specific factors that impact the promotion of breastfeeding at the local level. This area of knowledge is recognized by the WHO as a gab and considered it a research priority [13]. Therefore, this study aimed to identify the prevalence and factors associated with the practice of EBF among mothers in Hail city, Saudi Arabia.

\section{Materials and Methods}

2.1. Setting. A cross-sectional study was carried out between February and June 2019 in Hail city, in the north of Saudi Arabia, among mothers taking their children to one of six governmental primary healthcare (PHC) centers. PHC centers were selected at random between 24 centers covering all neighborhoods of Hail city. Among other services provided by PHC centers, well-baby and vaccination services are principal services provided free of charge. Vaccination of children is mandatory in Saudi Arabia, with coverage rates of 96-98\% for all vaccines in children aged one to two years [14]. Therefore, the selected mothers can be considered a representative sample.

2.2. Participants. The sample was selected using a two-stage sampling method. In the first stage; from the list of $24 \mathrm{PHC}$ centers, $25 \%$ of centers (six centers) were selected systematically with the first one at random. In the second stage, mothers of children 6-24 months, who visited the selected PHC centers seeking vaccination or routine checkup of their children, were randomly selected and invited to undergo an interview. Mothers were eligible if they were aged 18 years or over, with no medical condition preventing them or their children from breastfeeding.

2.3. Sample Size. The sample size was determined assuming that $50 \%$ of mothers practice EBF breastfeeding for up to six months to maximize sample size, a 95\% confidence level, and a $5 \%$ margin of error. The nonresponse rate was considered at $10 \%$; therefore, the final sample size was calculated to comprise 440 mothers.

2.4. Data Collection. Preparing for conducting the study, the authors visited the assigned PHC centers and met the directors of those centers, introduced the study objectives, and showed the official letters of the regional health authority to facilitate the study conduction and the letter of ethical approval. All centers approached agreed to participate. Data were collected through face-to-face interviews with the eligible mothers at random during the study period. One female researcher carried out all interviews with mothers who agreed to participate and gave their consent. The interviews were carried out privately for about 15 minutes.

2.5. Data Collection Tool. The interviews were carried out, guided by a questionnaire prepared by the study authors. Inquiries included in the questionnaire were based on previous relevant literature: international $[15,16]$, Middle East $[17,18]$, and Saudi Arabia [11, 19-21]. Other items that authors considered important to address the aims of the study were included. The questionnaire consisted of 4 parts: (1) sociodemographic characteristics of the participant mother; (2) mother's medical and obstetrical history, care received during pregnancy, labor, and puerperium; (3) information about the child characteristics and details about breastfeeding practice; and (4) mother's awareness, knowledge of breastfeeding, and source of information.

The face validity and content validity of the questionnaire were reviewed by a panel of 4 experts (pediatrician, nutritionist, family medicine, and public health). A pilot study done on 20 eligible mothers (not included in the final sample) was carried out before commencing the study; accordingly, the questionnaire was revised and modified to its final form.

2.6. Ethics. The study protocol was approved by the Bioethical Committee of the General Directorate of Health Affairs, Hail region, Saudi Arabia, with the ethical approval number being 2019-17. Agreed participants signed the study consent form.

2.7. Statistical Analysis. Data was entered, cleaned, and analyzed using Epi Info 7 (CDC, Atlanta, Georgia, US). Data was summarized using proportions for categorical data and mean and standard deviation for continuous data. The relationship was determined using chi-square for categorical variables and $T$-test or ANOVA test for continuous variables or nonparametric tests as applicable if data were not normally distributed.

Multivariable analysis was carried out using logistic regression analysis to find out factors independently associated with EBF practice among mothers. Mothers who practiced $\mathrm{EBF}($ no $=0$; yes $=1)$ were tested with predictor variables being assumed to affect this practice. Variables of the final model were determined using a stepwise backward 
removal method, deleting variables with a $p$ value above 0.25 in order to exclude the nonimportant variables from the model until the minimum adequate model was reached. Odds ratios (ORs) as well as their $95 \%$ confidence intervals (CIs) were calculated for the predictor variables in the analyses. All statistical tests were two-tailed, and differences were considered to be statistically significant at a $p$ value $\leq 0.05$.

\section{Results}

3.1. Mothers' Sociodemographic Characteristics. A total of 450 successful interviews out of 480 mothers asked to participate in the study, which yielded a response rate of $93.8 \%$. The main characteristics of the sample are described in Table 1. In particular, the average age of participating mothers was $30.2 \pm 7.48$ years. About half (45.6\%) attained a university degree or higher, while illiterate women constitute a small percent (5.8\%). Working mothers accounted for $30 \%$ of the participants.

\subsection{Obstetric History and Health Service-Related Factors.} The majority $(79.1 \%)$ of mothers were multigravida; $78.8 \%$ of them had more than one live child. The mean number of antenatal care visits received was 4 visits $(4.0 \pm 1.68)$ and $62.5 \%$ received postnatal care. The majority $(77.7 \%)$ received breastfeeding counseling during pregnancy and $79.9 \%$ immediately after delivery. Nearly all had given birth at full term (94.4\%) and delivered normally (93.8\%) at public hospitals $(90.7 \%)$. Most of them $(88.1 \%)$ breastfed their previous children (Table 1 ).

3.3. Awareness and Sources of Knowledge about Breastfeeding. Although $80.4 \%$ of mothers were aware of the concept of EBF and $72.9 \%$ of them correctly identified that exclusive breastfeeding means that the baby should receive only breast milk without any other supplements of any kind, only $21.6 \%$ of them correctly identified that the duration of EBF is for 6 months (Table 1). The main sources of the participants' knowledge about breastfeeding were Internet sites $(80.7 \%)$, social media $(74.0 \%)$, family and friends $(55.3 \%)$, posters and pamphlets $(32.7 \%)$, healthcare staff $(13.1 \%)$, television and radio (10.7\%), and school (4.4\%) (Figure 1).

3.4. Breastfeeding Practice. The pattern of newborn feeding during the hospital stay and after discharge was explored among participants (Table 1). According to the participants' responses, only $24 \%$ of mothers reported that they put their newborn on breast within one hour after delivery; however, $71.1 \%$ did during the first 24 hours. About half of the participants $(46.8 \%)$ initiated breastfeeding during their hospital stay, and $76.8 \%$ of them reported that they fed their newborn the colostrum; however, $50.1 \%$ had given their newborn a prelacteal feeding. The prevalence of EBF practice was $50.7 \%$ (95\% CI 45.9, 55.4\%). About $34.3 \%$ of the mothers were still breastfeeding their children during the study period.
3.5. Factors Associated with Exclusive Breastfeeding Practices. Results of the bivariate analysis to find the association between EBF and factors that might have influence are presented in Table 2. Factors that are found to be significantly associated with EBF and other important factors of interest are subsequently included in the multivariate logistic analysis to capture independent associations (Table 3). According to the multivariable logistic regression analysis, the following factors were positively associated with EBF practice: (i) mother's awareness about EBF (odds ratio (OR) 3.03; 95\% confidence interval (CI) 1.78-5.18), (ii) antenatal care received at governmental healthcare setting (OR 2.63; 95\% CI 1.28-5.41), (iii) history of breastfeeding of the previous child (OR 2.42; 95\% CI 1.46-4.03), (iv) breastfeeding counseling received after delivery (OR 2.47; 95\% CI 1.34-4.53), and (v) colostrum feeding given for the baby (OR 4.24; 95\% CI 2.31-7.77). On the other hand, (i) mother's education (OR 0.39; 95\% CI 0.15-0.99), (ii) higher family income (OR 0.04; 95\% CI 0.00-0.31), and (3) practice of prelacteal feeding (OR $0.61 ; 95 \%$ CI $0.38-0.97$ ) were negatively associated with EBF breastfeeding practice.

\section{Discussion}

Breastfeeding is an unequaled way of providing ideal food for the healthy growth and development of infants; it is also an integral part of the reproductive process with important implications for the health of mothers $[1,2,22]$. In 2012, the World Health Assembly (WHA) set a global target to increase the rate of EBF in the first 6 months up to at least $50 \%$ by 2025 [9]. The results of our study (50.7\% EBF rate) indicate that this target has been achieved in the urban community of the Hail region, Saudi Arabia. However, it is still far away from the widely accepted "universal coverage" target recommended by WHO/UNICEF that there should be $90 \% \mathrm{EBF}$ in children less than 6 months in developing countries [6,7]. The prevalence of EBF in our study is higher than some other recent reports in Saudi Arabia as shown in Tabouk (31.4\%; 2017) [19], Rabigh, at western region $(27.6 \% ; 2019)$ [23], and Taif $(16.3 \% ; 2019)$ [24] and as high as $37.0 \%$ (2018) in the capital Riyadh and Dammam main cities [21]. This wide variation in the rates of EBF was also reported in earlier regional reports in Saudi Arabia, which ranged from 0.8 to $43.9 \%$ [11]. The noticeable variation between studies indicates the importance of carrying out standardized national surveys covering all regions in the country to find out the national rate of EBF and to map the actual disparities between regions. National surveys should be conducted on a regular basis to observe the progress of the national strategies for breastfeeding promotion.

The relatively higher rate of EBF in our study challenges the conclusion that the EBF trend in Saudi Arabia is in decline [11], coping with the reported rising trend in developed countries [25].

Awareness about the concept of EBF among participants in our study was somewhat commendable (80.4\%). Mothers who were aware of EBF were independently three times more likely to exclusively breastfed their children, irrespective of 
TABLE 1: Sociodemographic, maternal, child, and health service characteristics reported by the study participants in Hail city, Saudi Arabia, 2019.

\begin{tabular}{|c|c|c|c|}
\hline Sociodemographic characteristics of the mother & $n$ & $(\%)$ & $95 \% \mathrm{CI}$ \\
\hline Mothers' age in years mean \pm SD (range) & & $30.16 \pm 7.48(18-48)$ & \\
\hline$<25$ & 110 & 24.4 & $20.6-28.7$ \\
\hline $25-29$ & 128 & 28.4 & $24.4-32.9$ \\
\hline $30-39$ & 128 & 28.4 & $24.4-32.9$ \\
\hline $40+$ & 84 & 18.7 & $15.2-22.6$ \\
\hline \multicolumn{4}{|l|}{ Mothers' education } \\
\hline Illiterate & 26 & 5.8 & $3.9-8.5$ \\
\hline Primary & 22 & 4.9 & $3.2-7.4$ \\
\hline Middle & 60 & 13.3 & $10.4-16.9$ \\
\hline Secondary & 137 & 30.4 & $26.3-35.0$ \\
\hline University/higher & 205 & 45.6 & $40.9-50.3$ \\
\hline \multicolumn{4}{|l|}{ Mothers' employment status } \\
\hline Working & 135 & 30.0 & $25.8-34.5$ \\
\hline Housewife & 269 & 59.8 & $55.1-64.3$ \\
\hline Student & 46 & 10.2 & $7.7-13.5$ \\
\hline \multicolumn{4}{|l|}{ Family income (SR) } \\
\hline$<3000$ & 16 & 3.6 & $2.1-5.8$ \\
\hline $3000-4999$ & 55 & 12.2 & $9.4-15.7$ \\
\hline $5000-9999$ & 148 & 32.9 & $28.6-37.5$ \\
\hline $10000-14999$ & 169 & 37.6 & $33.1-42.2$ \\
\hline$\geq 15000$ & 62 & 13.8 & $10.8-17.4$ \\
\hline \multicolumn{4}{|l|}{ Obstetric history and health service-related factors } \\
\hline \multicolumn{4}{|l|}{ Number of pregnancies mean \pm SD (range) $3.37 \pm 2.12(1-12)$} \\
\hline$<3$ & 67 & 15.2 & $12.0-18.9$ \\
\hline $3-4$ & 260 & 58.8 & $54.1-63.4$ \\
\hline$\geq 5$ & 115 & 26.0 & $22.0-30.4$ \\
\hline \multicolumn{4}{|c|}{ Number of children under 5 years mean \pm SD (range) $1.56 \pm 0.62(1-5)$} \\
\hline$\leq 1$ & 227 & 50.4 & $45.7-55.2$ \\
\hline$\geq 2$ & 223 & 49.6 & $44.8-54.3$ \\
\hline \multicolumn{4}{|l|}{ Sex of the child } \\
\hline Male & 293 & 53.1 & $48.4-57.8$ \\
\hline Female & 211 & 46.9 & $42.2-51.6$ \\
\hline \multicolumn{4}{|l|}{ Birth order of the child } \\
\hline First born & 107 & 23.8 & $20.0-28.0$ \\
\hline Second born & 106 & 23.6 & $19.8-27.8$ \\
\hline Third and above & 237 & 52.7 & $47.9-57.3$ \\
\hline \multicolumn{4}{|l|}{ No. of antenatal visits mean \pm SD (range) $3.97 \pm 1.68$ (1-9) } \\
\hline$<3$ & 75 & 16.7 & $13.4-20.5$ \\
\hline $3-4$ & 260 & 57.8 & $53.1-62.4$ \\
\hline $5+$ & 115 & 25.6 & $21.6-29.9$ \\
\hline \multicolumn{4}{|l|}{ Breastfeeding counseling received during antenatal care } \\
\hline Yes & 349 & 77.7 & $73.5-81.4$ \\
\hline No & 100 & 22.3 & $18.6-26.5$ \\
\hline \multicolumn{4}{|l|}{ Breastfeeding counseling received immediately after delivery } \\
\hline Yes & 358 & 79.9 & $75.8-83.5$ \\
\hline No & 90 & 20.1 & $16.5-24.2$ \\
\hline \multicolumn{4}{|l|}{ Mode of delivery } \\
\hline CS & 28 & 6.2 & $4.3-9.0$ \\
\hline Vaginal delivery & 421 & 93.8 & $91.0-95.7$ \\
\hline \multicolumn{4}{|l|}{ Place of delivery } \\
\hline Governmental hospital & 402 & 89.3 & $86.0-92.0$ \\
\hline Private hospital & 41 & 9.1 & $6.7-12.3$ \\
\hline \multicolumn{4}{|l|}{ Postnatal follow-up during puerperium } \\
\hline Yes & 280 & 62.5 & $57.8-67.0$ \\
\hline No & 168 & 37.5 & $33.0-42.2$ \\
\hline \multicolumn{4}{|l|}{ Awareness and knowledge about breastfeeding } \\
\hline Heard about exclusive breastfeeding (yes) & 362 & 80.4 & $76.4-83.9$ \\
\hline Know the meaning of EBF (breastfeeding only) & 328 & 72.9 & $68.5-76.9$ \\
\hline Know the duration of EBF (6 months) & 97 & 21.6 & $17.9-25.7$ \\
\hline What should be done with the colostrum (should be given) & 337 & 74.9 & $70.6-78.8$ \\
\hline
\end{tabular}


TABLE 1: Continued.

\begin{tabular}{|c|c|c|c|}
\hline Sociodemographic characteristics of the mother & $n$ & $(\%)$ & $95 \% \mathrm{CI}$ \\
\hline \multicolumn{4}{|l|}{ Breastfeeding practice of the current child } \\
\hline \multicolumn{4}{|l|}{ Time of initiation of breastfeeding } \\
\hline During $1^{\text {st }}$ hour of delivery & 108 & 24.0 & $20.2-28.3$ \\
\hline $2-24$ hours & 212 & 47.1 & $42.4-51.8$ \\
\hline$>24$ hours & 122 & 27.1 & $23.1-31.5$ \\
\hline Not breastfed at all & 8 & 1.8 & $0.8-3.6$ \\
\hline \multicolumn{4}{|l|}{ Place of initiation of breastfeeding } \\
\hline At the hospital & 210 & 46.8 & $42.1-51.5$ \\
\hline At home & 239 & 53.2 & $48.5-57.9$ \\
\hline \multicolumn{4}{|l|}{ Colostrum given to the newborn } \\
\hline Yes & 345 & 76.8 & $72.6-80.6$ \\
\hline No & 104 & 23.2 & $19.4-27.4$ \\
\hline \multicolumn{4}{|l|}{ Prelacteal feeding given to the newborn } \\
\hline Yes & 225 & 50.1 & $45.4-54.8$ \\
\hline No & 224 & 49.9 & $45.2-54.6$ \\
\hline \multicolumn{4}{|l|}{ Practiced exclusive breastfeeding } \\
\hline Yes & 226 & 50.7 & $45.9-55.4$ \\
\hline No & 220 & 49.3 & $44.6-54.1$ \\
\hline
\end{tabular}

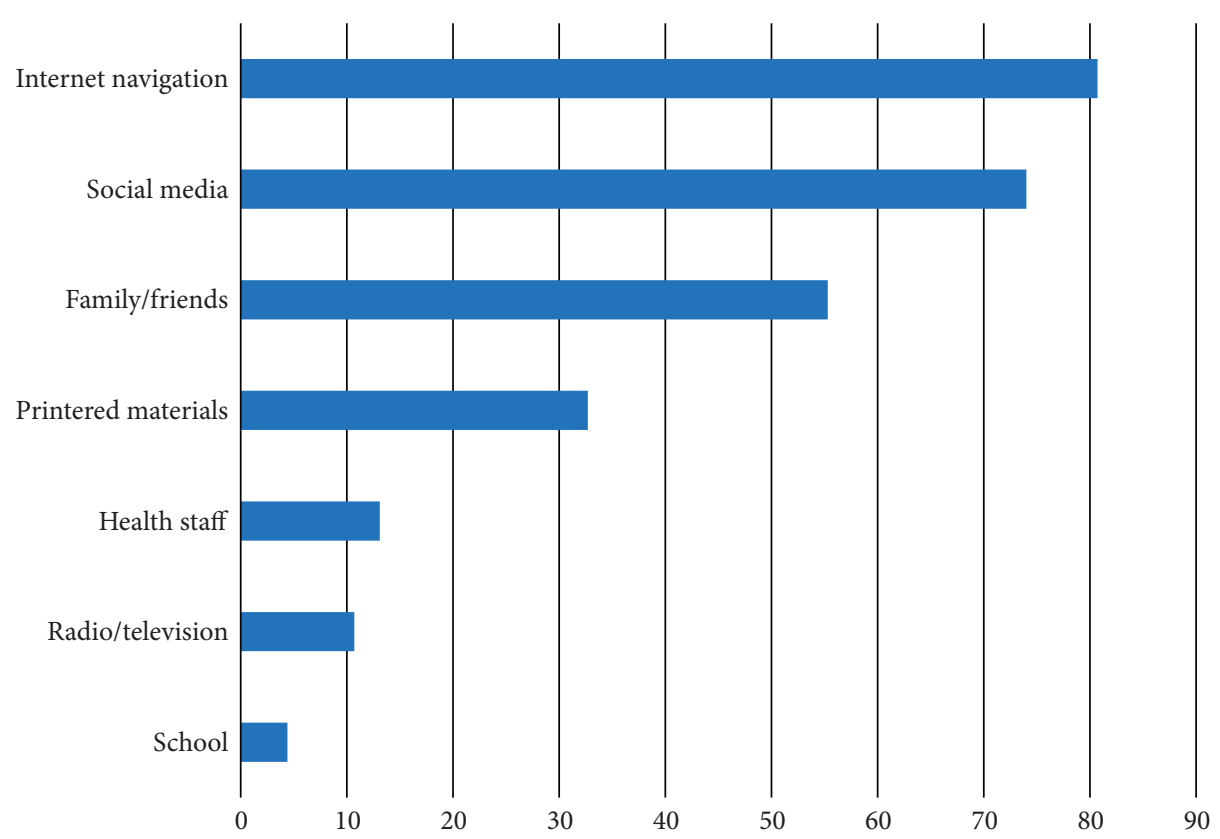

Figure 1: Frequency of use (\%) of different sources of knowledge about breastfeeding among participants. Participants may report more than one source of knowledge.

their education level. Similar findings have been reported by previous research [19] and indicate the importance of health education campaigns and other awareness programs to convey a clear message about the importance of EBF. Utilizing modern means of mass communication is of value since it is easily applicable and easily utilizable and will ensure a good diffusion of health education messages to a larger number of the target population and creates a positive norm toward breastfeeding in the community. Health information-seeking behavior among participants in our study indicated the heavy utilization of this means $(80.7 \%$ navigated Internet sites and $74.0 \%$ of them used social media to get information about breastfeeding).
Even though it is a natural act, breastfeeding is also a learned behavior. Virtually, all mothers can breastfeed provided that they have accurate information and support within their families and communities and from the healthcare system [22]. Our results showed that mothers who received breastfeeding counseling immediately after delivery were two and half times more likely to exclusively breastfeed their children compared to those who did not receive such counseling. This confirms the findings of other studies [26, 27]. Breastfeeding counseling during antenatal care and immediately after delivery together with other elements of the baby-friendly hospitals [28] is important institutional practice universally followed in maternity hospitals and other maternity departments in general 
TABLE 2: Bivariate analysis of factors associated with exclusive breastfeeding (EBF) practice among mothers in Hail city, Saudi Arabia, 2019.

\begin{tabular}{|c|c|c|c|c|}
\hline \multirow{2}{*}{ Variables } & \multicolumn{2}{|c|}{ Exclusive breastfeeding } & \multirow{2}{*}{ OR (95\% CI) } & \multirow{2}{*}{$p$ value } \\
\hline & Yes $(n=266 ; 50.7 \%)$ & No $(n=220 ; 49.3 \%)$ & & \\
\hline \multicolumn{5}{|c|}{ Sociodemographic characteristics of the mother } \\
\hline \multicolumn{5}{|c|}{ Mother's age (years) } \\
\hline$<25$ & $71(65.1)$ & $38(34.9)$ & $1.00[\mathrm{ref}]$ & 0.005 \\
\hline $25-29$ & $56(44.8)$ & $69(55.2)$ & $0.43(0.26-0.74)$ & 0.002 \\
\hline $30-39$ & $57(44.5)$ & $71(55.5)$ & $0.43(0.25-0.73)$ & 0.002 \\
\hline $40+$ & $42(50.0)$ & $42(50.0)$ & $0.54(0.30-0.96)$ & 0.035 \\
\hline \multicolumn{5}{|l|}{ Mother's education } \\
\hline Illiterate & $14(53.8)$ & $12(46.2)$ & $1[\mathrm{ref}]$ & 0.033 \\
\hline Primary & $12(54.5)$ & $10(45.5)$ & $1.03(0.33-3.22)$ & 0.961 \\
\hline Middle & $23(38.3)$ & $37(61.7)$ & $0.53(0.21-1.35)$ & 0.185 \\
\hline Secondary & $59(44.0)$ & $75(56.0)$ & $0.67(0.29-1.57)$ & 0.360 \\
\hline University/higher & $118(57.8)$ & $86(42.2)$ & $1.18(0.52-2.67)$ & 0.698 \\
\hline \multicolumn{5}{|l|}{ Mother's employment status } \\
\hline Working & $76(56.3)$ & $59(43.7)$ & $1[\mathrm{ref}]$ & 0.005 \\
\hline Housewife & $119(44.9)$ & $146(55.1)$ & $0.63(0.42-0.96)$ & 0.032 \\
\hline Student & $31(67.4)$ & $15(32.6)$ & $1.60(0.79-3.24)$ & 0.188 \\
\hline \multicolumn{5}{|l|}{ Family income (SR) } \\
\hline$<3000$ & $14(93.3)$ & $1(6.70)$ & $1[\mathrm{ref}]$ & \\
\hline $3000-4999$ & $26(48.1)$ & $28(51.9)$ & $0.07(0.01-0.54)$ & 0.011 \\
\hline $5000-9999$ & $65(44.2)$ & $82(55.8)$ & $0.06(0.01-0.44)$ & 0.006 \\
\hline $10000-14999$ & $89(53.0)$ & $79(47.0)$ & $0.08(0.01-0.63)$ & 0.016 \\
\hline$\geq 15000$ & $32(51.6)$ & $30(48.4)$ & $0.08(0.01-0.62)$ & 0.016 \\
\hline \multicolumn{5}{|c|}{ Obstetric history and health service-related factors } \\
\hline \multicolumn{5}{|c|}{ No. of pregnancies } \\
\hline$<3$ & $37(55.2)$ & $30(44.8)$ & $1[\mathrm{ref}]$ & \\
\hline $3-4$ & $139(53.9)$ & $119(46.1)$ & $0.95(0.55-1.63)$ & 0.844 \\
\hline $5+$ & $46(40.7)$ & $67(59.3)$ & $0.56(0.30-1.02)$ & 0.060 \\
\hline \multicolumn{5}{|c|}{ No. of children under 5 years } \\
\hline$\leq 1$ & $123(55.2)$ & $100(44.8)$ & $1[\mathrm{ref}]$ & \\
\hline$\geq 2$ & $103(46.2)$ & $120(53.8)$ & $0.70(0.48-1.01)$ & 0.059 \\
\hline \multicolumn{5}{|c|}{ History of breastfeeding the previous child } \\
\hline Yes & $79(63.7)$ & $113(40.1)$ & \multirow[b]{2}{*}{$2.63(1.70-4.06)$} & \multirow{2}{*}{$<0.001$} \\
\hline No & $45(36.3)$ & $169(59.9)$ & & \\
\hline \multicolumn{5}{|c|}{ Information about the child under investigation } \\
\hline Facility where antenatal ca & & & & \\
\hline Governmental & $210(54.3)$ & $177(45.7)$ & & \\
\hline Private & $16(27.1)$ & $43(72.9)$ & $3.19(1.74-5.86)$ & $<0.001$ \\
\hline No. of antenatal visits & & & & \\
\hline$<3$ & $37(55.2)$ & $30(44.8)$ & $1[\mathrm{ref}]$ & \\
\hline $3-4$ & $139(53.9)$ & $119(46.1)$ & $0.95(0.55-1.63)$ & 0.844 \\
\hline $5+$ & $46(40.7)$ & $67(59.3)$ & $0.56(0.30-1.02)$ & 0.060 \\
\hline Breastfeeding counseling $r$ & al care visits & & & \\
\hline Yes & $184(53.3)$ & $161(46.7)$ & $1.58(1.01-2.48)$ & 0.046 \\
\hline No & $42(42.0)$ & $58(58.0)$ & $1[\mathrm{ref}]$ & \\
\hline Place of delivery & & & & \\
\hline Governmental hospital & $206(51.8)$ & $192(48.2)$ & $1.68(0.87-3.23)$ & 0.120 \\
\hline Private hospital & $16(39.0)$ & $25(61.0)$ & $1[\mathrm{ref}]$ & \\
\hline Mode of delivery & & & & \\
\hline CS & $12(42.9)$ & $16(57.1)$ & $1[\mathrm{ref}]$ & \\
\hline Normal delivery & $213(51.1)$ & $204(48.9)$ & $1.39(0.64-3.02)$ & 0.401 \\
\hline Sex of the child & & & & \\
\hline Male & $118(50.2)$ & $117(49.8)$ & $1[\mathrm{ref}]$ & \\
\hline Female & $108(51.2)$ & $103(48.8)$ & $1.04(0.72-1.51)$ & 0.838 \\
\hline Birth order of the child & & & & \\
\hline First born & $62(58.5)$ & $44(41.5)$ & $1[\mathrm{ref}]$ & \\
\hline Second born & $59(56.2)$ & $46(43.8)$ & $0.91(0.53-1.57)$ & 0.736 \\
\hline Third and above & $105(44.7)$ & $130(55.3)$ & $0.57(0.36-0.91)$ & 0.019 \\
\hline Breastfeeding counseling $r$ & fter delivery & & & \\
\hline Yes & $199(56.2)$ & $155(43.8)$ & $3.34(2.01-5.54)$ & $<0.001$ \\
\hline
\end{tabular}


TABLE 2: Continued.

\begin{tabular}{|c|c|c|c|c|}
\hline \multirow{2}{*}{ Variables } & \multicolumn{2}{|c|}{ Exclusive breastfeeding } & \multirow{2}{*}{ OR $(95 \% \mathrm{CI})$} & \multirow{2}{*}{$p$ value } \\
\hline & Yes $(n=266 ; 50.7 \%)$ & No $(n=220 ; 49.3 \%)$ & & \\
\hline No & $25(27.8)$ & $56(72.2)$ & $1[\mathrm{ref}]$ & \\
\hline \multicolumn{5}{|c|}{ Initiation of breastfeeding } \\
\hline $1^{\text {st }}$ hour & $71(67.0)$ & $35(33.0)$ & $2.42(1.53-3.83)$ & $<0.001$ \\
\hline$>1$ hour & $155(45.6)$ & $185(54.4)$ & $1[\mathrm{ref}]$ & \\
\hline \multicolumn{5}{|l|}{ Received colostrum } \\
\hline Yes & $204(59.6)$ & $138(40.4)$ & $5.51(3.28-9.25)$ & $<0.001$ \\
\hline No & $22(21.2)$ & $82(78.8)$ & $1[\mathrm{ref}]$ & \\
\hline \multicolumn{5}{|l|}{ Prelacteal feeding } \\
\hline Yes & $100(44.8)$ & $123(55.2)$ & $1[\mathrm{ref}]$ & 0.016 \\
\hline No & $125(56.3)$ & $97(43.7)$ & $1.59(1.09-2.30)$ & \\
\hline \multicolumn{5}{|c|}{ Postnatal follow-up during puerperium } \\
\hline Yes & $149(62.3)$ & $35(29.4)$ & $3.97(2.48-6.38)$ & $<0.001$ \\
\hline No & $90(37.7)$ & $84(70.6)$ & $1[\mathrm{ref}]$ & \\
\hline \multicolumn{5}{|c|}{ Awareness and knowledge about breastfeeding } \\
\hline \multicolumn{5}{|c|}{ Heard about EBF } \\
\hline Yes & $77(63.1)$ & $143(44.1)$ & $2.17(1.41-3.32)$ & $<0.001$ \\
\hline No & $45(36.9)$ & $181(55.9)$ & 1 & \\
\hline \multicolumn{5}{|c|}{ Know the meaning of EBF } \\
\hline Breastfeeding only & $185(51.5)$ & $174(48.5)$ & $1.19(0.75-1.91)$ & 0.460 \\
\hline Other options & $41(47.1)$ & $46(52.9)$ & 1 & \\
\hline \multicolumn{5}{|c|}{ What should be done with the colostrum } \\
\hline Should be given & $193(57.8)$ & $141(42.2)$ & $3.28(2.07-5.20)$ & $<0.001$ \\
\hline Should be discarded & $33(29.5)$ & $79(70.5)$ & 1 & \\
\hline
\end{tabular}

TABLE 3: Multivariate logistic regression model for independent predictors of practice exclusive breastfeeding among mothers in Hail city, Saudi Arabia, 2019.

\begin{tabular}{|c|c|c|c|}
\hline Variables & $\mathrm{aOR}$ & $95 \% \mathrm{CI}$ & $p$ value \\
\hline Education (educated/illiterate) & 0.39 & $0.15-0.99$ & 0.047 \\
\hline Family income $(\leq 3000 />3000$ SR $)$ & 0.04 & $0.00-0.31$ & 0.002 \\
\hline Aware about exclusive breastfeeding (yes/no) & 3.03 & $1.78-5.18$ & $<0.001$ \\
\hline History of breastfeeding the previous child (yes/no) & 2.42 & $1.46-4.03$ & $<0.001$ \\
\hline Facility where antenatal care received (governmental/private) & 2.63 & $1.28-5.41$ & 0.009 \\
\hline Breastfeeding counselling/support received immediately after delivery (yes/no) & 2.47 & $1.34-4.53$ & 0.004 \\
\hline Colostrum feed given (yes/no) & 4.24 & $2.31-7.77$ & $<0.001$ \\
\hline Prelacteal feeding given (yes/no) & 0.61 & $0.38-0.97$ & 0.038 \\
\hline
\end{tabular}

Abbreviations: $\mathrm{aOR}=$ adjusted odds ratio; $\mathrm{SE}=$ standard error; $\mathrm{CI}=$ confidence interval; $\mathrm{SR}=$ Saudi riyal, equivalent to $0.27 \mathrm{US} \$$. Final $-2 *$ log-likelihood: 450.2881; cases included: 402; likelihood ratio: 105.5686; $p$ value $<0.001$.

hospitals in the Hail region, applying the initiative of babyfriendly hospitals. However, adherence to these regulations is not tightly followed in private healthcare facilities, as revealed from the analysis of our study, where mothers who received antenatal care in governmental healthcare facilities were independently more than two and half times more likely to exclusively breastfed their children compared to those who received antenatal care in private facilities. This indicates that government healthcare facilities are more compliant with the guidelines of WHO/UNICEF and the Ministry of Health regarding breastfeeding promotion compared to private healthcare facilities. It implies also that the private healthcare facilities should be supervised well to comply with the initiative of baby-friendly hospitals and training of healthcare staff and tightly apply the code of marketing human milk substitutes.

There should be compliance with breastfeeding promotion guidelines regarding initiating breastfeeding early after delivery, giving colostrum to the newborn, and not giving any prelacteal feeds which were independent predictors of EBF practice among our study participants. Mothers who initiated breastfeeding early by giving colostrum to their newborns were more than 4 times more likely to exclusively breastfeed their children, and those who did not give a prelacteal feeding were one and half times independently more likely to exclusively breastfeed their children. This finding supports reports of other research studies [20]. These practices mostly occur after delivery while the mother is still in the hospital so that maternal counseling and support are two crucial approaches to promote EBF among mothers to be emphasized.

In our analysis, we found that educated mothers were independently more likely to discontinue EBF compared to illiterate ones. Educated mothers in general were $60 \%$ less likely to exclusively breastfed their children as revealed by logistic regression analysis compared to illiterate ones. This finding is also reported in some other research studies from 


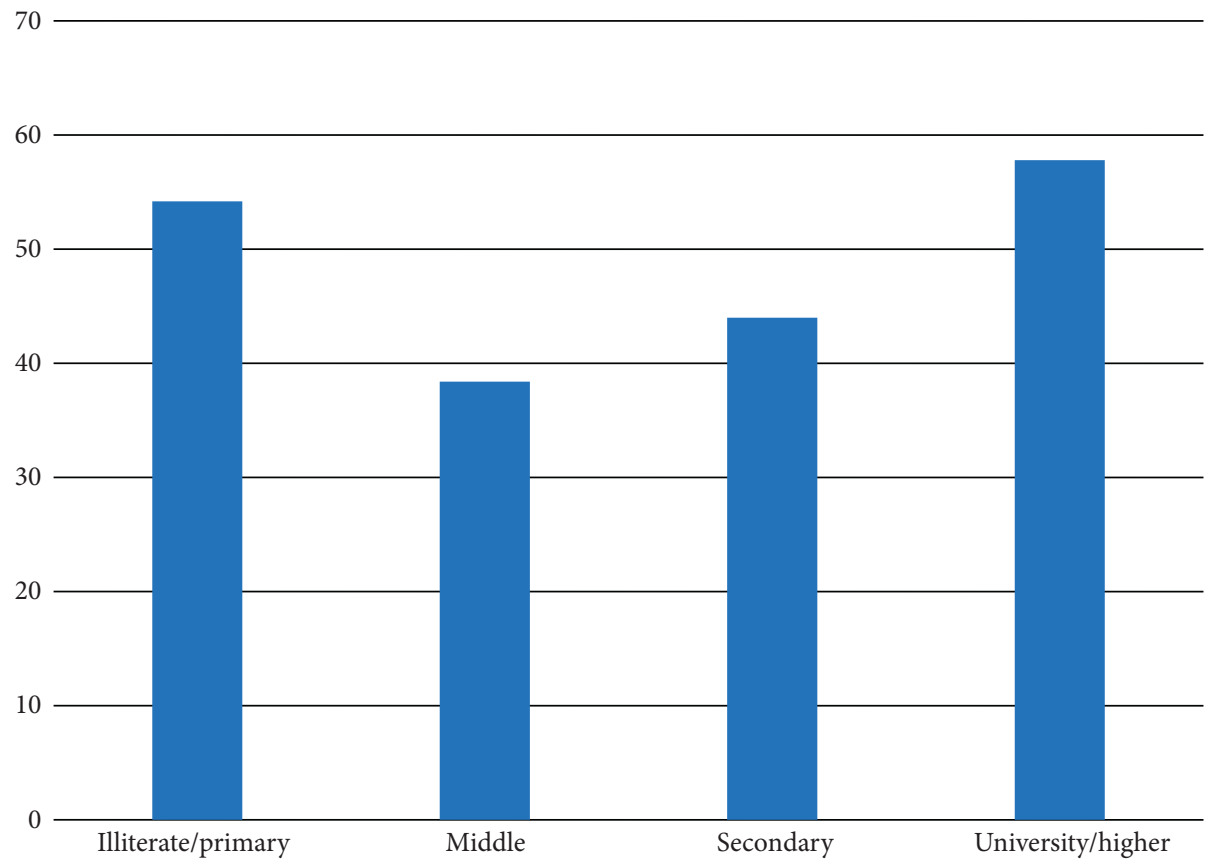

Figure 2: Prevalence of exclusive breastfeeding practice among mothers at education levels.

Saudi Arabia and developing countries [11, 20, 29-32]. However, education in the bivariate analysis in our study showed a U-shaped association (Figure 2), where mothers who were illiterate or just have primary schooling (EBF $54.2 \%)$ and those with university or higher level of education (EBF 57.8\%) were more adherents to EBF, compared to mothers with middle (EBF 38.3\%) or secondary schooling (EBF 44.0\%). A possible explanation for these findings for the illiterate/low educated mothers is the more intimacy to the traditional life, where breastfeeding is seen as the main role and the responsibility of motherhood and is a translation of what was seen and practiced by their mothers. Mothers with university or higher education might potentially have higher breastfeeding literacy and be convinced of the importance of breastfeeding for child and mother's health as seen in developed countries [33-36]. The U-shaped effect of a mother's education on adherence to breastfeeding might explain in part the conflicting results of studies that reported a positive association and those that reported a negative one.

Poorer mothers in our study with the least monthly family income were more adherent to EBF than those with higher family income. Similar findings have been described by previous studies, which point to the fact that the higher the family income, the less preference toward breastfeeding $[11,20,37,38]$. This may be explained in part by not having the choice of paying for formula milk and may be less exposed to the adverse effect of formula milk advertising which targets the more privileged mothers.

Limitations in this study include the cross-sectional design, which limits the ability to infer the causation between predictor variables and EBF practice. Using an interview survey may lead to social desirability bias and also recall bias cannot be eliminated. Study participants in our study were completely from the urban population in Hail city, so the generalizability of the result cannot be extended to the rural population in the region. However, the current study provides insight into the rate and factors affecting the adoption of EBF among mothers in the region. Understanding these factors will provide a guide for policymakers and healthcare staff to plan effective breastfeeding health promotion programs to enhance EBF among mothers in the region.

\section{Conclusion}

Our study revealed a relatively higher EBF rate among mothers in Hail region urban community compared to some other regions in Saudi Arabia. Results, also, revealed a number of important modifiable individual and institutional risk factors affecting EBF practice that may be informative when planning for breastfeeding promotion in the region. Adherence to WHO/UNICEF and $\mathrm{MOH}$ guidelines for breastfeeding promotion appears to be of value, especially in the private sector.

\section{Data Availability}

The data used to support the findings of this study are available from the corresponding author upon request.

\section{Conflicts of Interest}

The authors declare no conflicts of interest.

\section{Authors' Contributions}

MA conceived the study idea, participated in the development of the data collection tool, carried out the interviews with the participants, and participated in the interpretation of the study results. HH adapted the study idea, developed 
the study protocol and data collection tool, carried out data analysis and interpretation of results, and wrote the manuscript. All authors critically revised and approved the final version of the manuscript.

\section{Acknowledgments}

The authors thank the directors and healthcare staff in PHC centers, Hail city, Saudi Arabia, for facilitating the study conduction in their centers. They also thank the participant mothers for their agreement, patience, and allowing them time to carry out the interview with them.

\section{References}

[1] World Health Organization (WHO), Breastfeeding Overview, World Health Organization (WHO), Geneva, Switzerland, 2020, https://www.who.int/health-topics/breastfeeding\#tab= tab_2.

[2] Centers for Disease Control and Prevention (CDC), Breastfeeding, Centers for Disease Control and Prevention (CDC), Atlanta, GA, USA, 2020, https://www.cdc.gov/breastfeeding/ about-breastfeeding/why-it-matters.html.

[3] R. E. Azuine, J. Murray, N. Alsafi, and G. K. Singh, "Exclusive breastfeeding and under-five mortality, 2006-2014: a crossnational analysis of 57 low- and-middle income countries," International Journal of MCH and AIDS, vol. 4, no. 1, 2015.

[4] World Health Organization (WHO), Indicator Metadata Registry List, World Health Organization (WHO), Geneva, Switzerland, 2020, https://www.who.int/data/gho/indicatormetadata-registry/imr-details/130.

[5] World Health Organization (WHO), Breastfeeding Factsheets. Infant and Young Child Feeding, World Health Organization (WHO), Geneva, Switzerland, 2020, https://www.who.int/ news-room/fact-sheets/detail/infant-and-young-childfeeding.

[6] G. Jones, R. W. Steketee, R. E. Black, Z. A. Bhutta, and S. S. Morris, "How many child deaths can we prevent this year?" The Lancet, vol. 362, no. 9377, pp. 65-71, 2003.

[7] World Health Organization (WHO)/, The United Nations Children's Fund (UNICEF): Global Action Plan for Prevention and Control of Pneumonia (GAPP), World Health Organization (WHO), Geneva, Switzerland, 2009, https://apps.who. int/iris/bitstream/handle/10665/70101/WHO_FCH_CAH_N CH_09.04_eng.pdf;jsessionid=555A95E358F05C8C4DB0553 47C71C5FC? sequence $=1$.

[8] World Health Organization (WHO), Regional Office for the Eastern Mediterranean. Regional Strategy on Nutrition 2010-2019/, World Health Organization (WHO), Geneva, Switzerland, 2011, https://applications.emro.who.int/dsaf/ dsa1230.pdf.

[9] World Health Organization (WHO), Resolution WHA65.6. Sixty-Fifth World Health Assembly Geneva, World Health Organization (WHO), Geneva, Switzerland, 2012, https:// www.who.int/nutrition/topics/WHA65.6_resolution_en.pdf? ua $=1$.

[10] M. I. El Mouzan, A. A. Al Omar, A. A. Al Salloum, A. S. Al Herbish, and M. M. Qurachi, "Trends in infant nutrition in Saudi Arabia: compliance with WHO recommendations," Annals of Saudi Medicine, vol. 29, no. 1, pp. 20-23, 2009.

[11] D. A. Al Juaid, C. W. Binns, and R. C. Giglia, "Breastfeeding in Saudi Arabia: a review," International Breastfeeding Journal, vol. 9, no. 1, 2014.
[12] World Health Organization (WHO), Nutrition Landscape Information System, Saudi Arabia Country Profile, World Health Organization (WHO), Geneva, Switzerland, 2020, https://apps.who.int/nutrition/landscape/global-monitoringframework?ISO=SAU.

[13] World Health Organization (WHO), Guideline: Protecting, Promoting and Supporting Breastfeeding in Facilities Providing Maternity and Newborn Services, World Health Organization (WHO), Geneva, Switzerland, 2017, https://apps. who.int/iris/bitstream/handle/10665/259386/978924155008 6-eng.pdf;jsessionid=B3C8F1E5DB89F6AAC2B75D077C90 $\mathrm{AB} 0 \mathrm{~B}$ ? sequence $=1$.

[14] World Health Organization (WHO), Vaccine-Preventable Diseases: Monitoring System. 2019 Global Summary, World Health Organization (WHO), Geneva, Switzerland, 2020, https://apps.who.int/immunization_monitoring/globalsum mary/countries?countrycriteria $\% 5 \mathrm{Bcountry} \% 5 \mathrm{D} \% 5 \mathrm{~B} \% 5 \mathrm{D}=$ SAU.

[15] E. Mangrio, K. Persson, and A.-C. Bramhagen, "Sociodemographic, physical, mental and social factors in the cessation of breastfeeding before 6 months: a systematic review," Scandinavian Journal of Caring Sciences, vol. 32, no. 2, pp. 451-465, 2018.

[16] A. Cernigliaro, S. Palmeri, P. Immordino et al., "Allattamento al seno in Sicilia: analisi della prevalenza, delle disuguaglianze di contesto e di altri fattori di rischio associati (Breastfeeding in Sicily Region (Southern Italy): analysis of prevalence, of contextual inequalities, and of other associated risk factors)," Journal of Preventive Epidemiology, vol. 42, no. 5-6, pp. 301307, 2018.

[17] R. A. Alzaheb, "Review of the factors associated with the timely initiation of breastfeeding and exclusive breastfeeding in the Middle East," Clinical Medicine Insights Pediatric Journal, vol. 11, 2017.

[18] M. Behzadifar, M. Saki, M. Behzadifar et al., "Prevalence of exclusive breastfeeding practice in the first six months of life and its determinants in Iran: a systematic review and metaanalysis," BMC Pediatrics, vol. 19, no. 1, p. 384, 2019.

[19] R. A. Alzaheb, "Factors influencing exclusive breastfeeding in Tabuk, Saudi Arabia," Clinical Medicine Insights: Pediatrics, vol. 11, 2017.

[20] A.-H. El-Gilany, E. Shady, and R. Helal, "Exclusive breastfeeding in Al-Hassa, Saudi Arabia," Breastfeeding Medicine, vol. 6, no. 4, pp. 209-213, 2011.

[21] H. Raheel and S. Tharkar, "Why mothers are not exclusively breast feeding their babies till 6 months of age? Knowledge and practices data from two large cities of the Kingdom of Saudi Arabia," Sudanese Journal of Paediatrics, vol. 18, no. 1, pp. 28-38, 2018.

[22] World Health Organization (WHO), Global Strategy for Infant and Young Child Feeding, World Health Organization (WHO), Geneva, Switzerland, 2003, https://apps.who.int/iris/ bitstream/handle/10665/42590/9241562218.pdf.

[23] M. A. Hegazi, M. Allebdi, M. Almohammadi, A. Alnafie, L. AlHazmi, and S. Alyoubi, "Factors associated with exclusive breastfeeding in relation to knowledge, attitude and practice of breastfeeding mothers in Rabigh Community, Western Saudi Arabia," World Journal of Pediatrics, vol. 15, no. 6, pp. 601-609, 2019.

[24] N. Alsulaimani, "Exclusive breastfeeding among Saudi mothers: exposing the substantial gap between knowledge and practice," Journal of Family Medicine and Primary Care, vol. 8, no. 9, pp. 2803-2809, 2019. 
[25] C. G. Victora, R. Bahl, A. J. Barros et al., "Lancet Breastfeeding Series Group. Breastfeeding in the 21st century: epidemiology, mechanisms, and lifelong effect," The Lancet, vol. 387, no. 10017, pp. 475-490, 2016.

[26] M. T. Hunegnaw, L. D. Gezie, and A. S. Teferra, "Exclusive breastfeeding and associated factors among mothers in Gozamin District, Northwest Ethiopia: a community based cross-sectional study," International Breastfeeding Journal, vol. 12, no. 1, p. 30, 2017.

[27] S. A. Ochola, D. Labadarios, and R. W. Nduati, "Impact of counselling on exclusive breast-feeding practices in a poor urban setting in Kenya: a randomized controlled trial," Public Health Nutrition, vol. 16, no. 10, pp. 1732-1740, 2013.

[28] World Health Organization (WHO), Baby-Friendly Hospital Initiative: Revised, Updated and Expanded for Integrated Care, World Health Organization, Geneva, Switzerland, 2009, http://www.ncbi.nlm.nih.gov/books/NBK153471/.

[29] R. Karkee, A. H. Lee, V. Khanal, and C. W. Binns, "A community-based prospective cohort study of exclusive breastfeeding in Central Nepal," BMC Public Health, vol. 14927 pages, 2014.

[30] D. M. Abdel-Hady and A.-H. El-Gilany, "Calculating exclusive breastfeeding rates: comparing dietary "24-hour recall" with recall "since birth" methods," Breastfeeding Medicine, vol. 11, no. 10, pp. 514-518, 2016.

[31] K. Velusamy, P. Premkumar, and G. Kang, "Exclusive breastfeeding practices among mothers in urban slum settlements: pooled analysis from three prospective birth cohort studies in South India," International Breastfeeding Journal, vol. 12, no. 1, p. 35, 2017.

[32] J. Zhao, Y. Zhao, M. Du, C. W. Binns, and A. H. Lee, "Maternal education and breastfeeding practices in China: a systematic review and meta-analysis," Midwifery, vol. 50, pp. 62-71, 2017.

[33] K. Vanderlinden and B. Van de Putte, "Pathways of equality through education: impact of gender (in)equality and maternal education on exclusive breastfeeding among natives and migrants in Belgium," Maternal \& Child Nutrition, vol. 13, no. 2, p. e12309, 2017.

[34] M. Bonet, L. Foix L'Hélias, and B. Blondel, “Allaitement maternel exclusif et allaitement partiel en maternité: la situation en France en 2003," Archives de Pédiatrie, vol. 15, no. 9, pp. 1407-1415, 2008.

[35] M. D. M. Whipps, "Education attainment and parity explain the relationship between maternal age and breastfeeding duration in U.S. mothers," Journal of Human Lactation, vol. 33, no. 1, pp. 220-224, 2017.

[36] P.-C. Chang, S.-F. Li, H.-Y. Yang et al., "Factors associated with cessation of exclusive breastfeeding at 1 and 2 months postpartum in Taiwan," International Breastfeeding Journal, vol. 14, no. 1, p. 18, 2019.

[37] N. Andrieu, D. E. Goldgar, D. F. Easton et al., "Pregnancies, breast-feeding, and breast cancer risk in the international BRCA1/2 Carrier Cohort Study (IBCCS)," JNCI: Journal of the National Cancer Institute, vol. 98, no. 8, pp. 535-544, 2006.

[38] S. S. Diab, A. K. Alrwely, A. A. Elanzy, A. R. Elkwikeby, and N. Turky, "Effects of decline exclusive breastfeeding practice among Saudi adolescent mothers and its risks on the mothers' and infants' health at jouf region," International Journal of Pediatrics and Neonatal Health, vol. 3, no. 3, pp. 32-39, 2019, https://biocoreopen.org/ijpn/Effects-ofDecline-Exclusive-Breastfeeding-Practice.php. 